\title{
AREA-WIDE MANAGEMENT OF STABLE FLIES
}

\author{
D. B. TAYLOR
}

Agroecosystem Management Research Unit, USDA-ARS, Lincoln, Nebraska,USA; Dave.Taylor@ARS.USDA.GOV

\begin{abstract}
SUMMARY
Stable flies are highly vagile and their dispersal ability appears to be limited only by the availability of hosts. In addition, stable fly larval developmental substrates are diverse, dispersed and often difficult to locate. This life history necessitates the use of area-wide integrated pest management (AW-IPM) strategies if effective control of stable flies is to be achieved, but complicates the use of the Sterile Insect Technique (SIT) and mating disruption technologies often employed in such programmes against other insect pests. Area-wide management of stable flies will require nationally or regionally coordinated implementation of traditional control methods, including sanitation/cultural, biological, and chemical technologies. An administrative structure will need to be implemented to coordinate, monitor, inspect and enforce compliance, especially if agronomic crop residues are integral to stable fly infestations. Research on stable fly developmental substrates and their management, larval and adult population dynamics, efficient and economical adult suppression systems, including traps and targets, is needed to improve the efficiency and economy of area-wide management of stable flies.
\end{abstract}

Key Words: Stomoxys calcitrans, control, IPM, livestock, dispersal, crop residues, regional coordination, filth flies

\section{INTRODUCTION}

Stable flies, Stomoxys calcitrans (L.), are important, pests of livestock throughout much of the world. Their painful bites disrupt feeding and other behaviours of livestock (Dougherty et al. 1993, 1994, 1995; Mullens et al. 2006), reducing productivity (Campbell et al. 1993, 2001) and, in extreme infestations, resulting in mortality (Bishopp 1913). In addition to their effects upon cattle, stable flies disrupt human recreational activities (Newson 1977) and molest companion animals (Yeruham and Braverman 1995) and wildlife (Elkan et al. 2009) throughout their range. Landing counts of 80-100 flies per minute on humans have been observed on the beaches of north-western Florida (Hogsette et al. 1987).

Adult stable flies are obligate hematophages, both males and females require blood prior to mating (Anderson 1978). Females need 3-4 blood meals to develop 
their first batch of eggs and 2 more for each additional batch (Bishopp 1913; Anderson and Tempelis 1970). After feeding, stable flies retire to a nearby surface, frequently warmed by the sun, to digest their blood meal. Immature stable flies develop in decaying or fermenting vegetative materials frequently contaminated with animal dung or urine (Simmons and Dove 1941, 1942; Silverly and Schoof 1955; Hafez and Gamal-Eddin 1959; Campbell and McNeal 1979; Hall et al. 1982) where larval densities can exceed 20000 per square-meter of substrate (Patterson and Morgan 1986; Broce et al. 2005).

Four species of flies, face fly (Musca autumnalis De Geer), house fly (Musca domestica L.), horn fly (Haematobia irritans (L.)), and stable fly are frequently found in association with livestock. Often, these flies are referred to collectively as "filth flies." Although morphologically similar, the behaviour and biology of these flies are distinct (Moon 2002; Zumpt 1973). Stable fly and horn fly are obligate parasites, primarily of livestock, with biting mouth parts. Face fly and house fly are non-biting flies with sponging mouthparts. Face fly and horn fly larvae develop in fresh, undisturbed bovine dung. Stable fly and house fly larvae develop in older or aged manure, frequently mixed with decomposing vegetative material as well as decomposing non-manure substrates. Horn flies are semi-permanent parasites, spending the majority of their adult life on a host, whereas stable flies are temporary parasites, visiting the host only to blood-feed. Face flies are obligate parasites as well, but rather than feeding on blood, they feed on mucus and other fluids around the eyes and mouth of the host. Because of these biological differences, many of the technologies and methods used for their management are species-specific. Proper identification of the offending fly species is essential before initiating a management programme.

\section{DEVELOPMENT IN CROP RESIDUES}

Many types of decomposing and fermenting organic materials support stable fly larval development (Hogsette et al. 1987), although in North America most practitioners consider residues from livestock production systems and barnyards to be the primary sources. This, however, has not always been the case. In the first half of the $20^{\text {th }}$ century, straw of oats, rice, barley, and wheat were reportedly the most common developmental substrates. Population levels were correlated with grain production (Bishopp 1913) and severe stable fly outbreaks were attributed to development in peanut straw, celery and bay grass (Dove and Simmons 1941, 1942). Recently, agronomic crop residues have re-emerged as important sources of stable flies. Serious outbreaks associated with pineapple production have been reported in Costa Rica (Herrero et al. 1989, 1991), sugarcane in Brazil and Mauritius (Kunz and Monty 1976; Koller et al. 2009; Souza Dominghetti et al. 2015), and vegetable crop residues in Western Australia (Cook et al. 1999). Counts of greater than 2000 stable flies per animal are being associated with development in crop residues (Fig. 1). 
This gives rise to one of the primary differences between the stable fly situation in the USA and that in Australia, Brazil, Costa Rica, and potentially other countries. In the USA, stable fly larval developmental sites are typically associated with livestock production. In a sense, livestock producers are responsible for the problem they perceive. Where stable fly developmental sites are being attributed to agronomic production and crop residues (e.g. Australia, Brazil and Costa Rica), another industry, or someone else, is responsible for the problem. Calls for regulation and government action are louder when someone else is to blame.

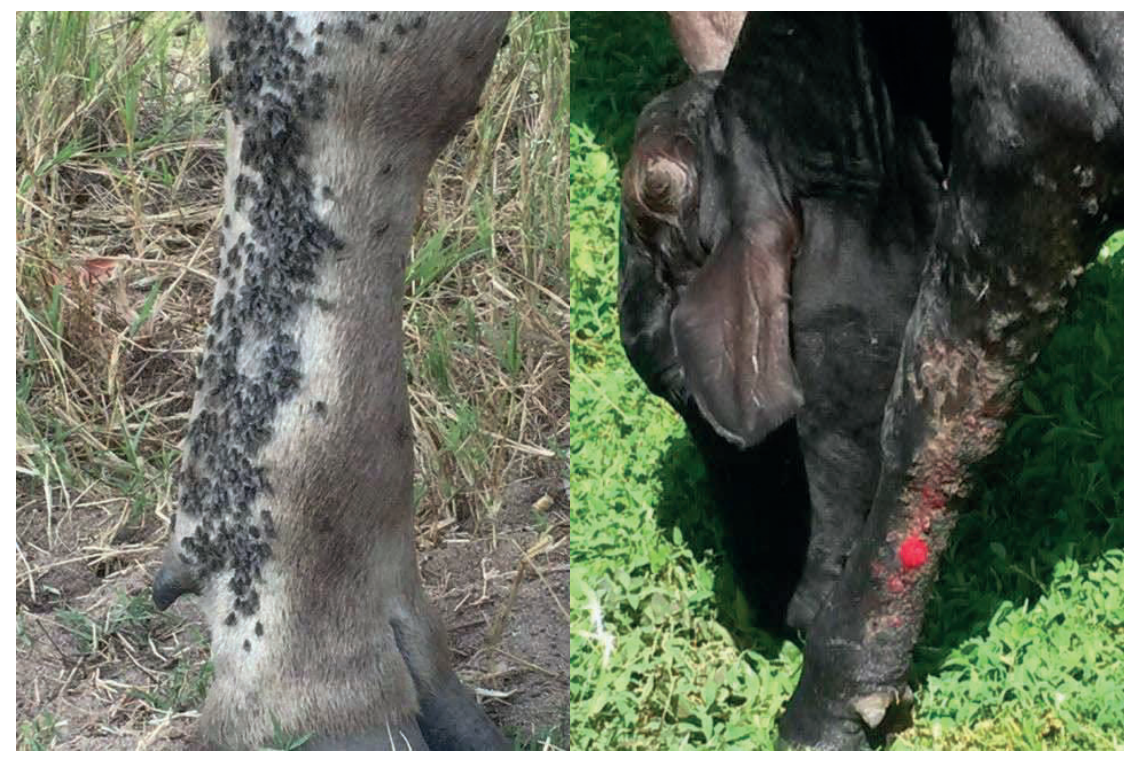

Figure 1. Stable flies on leg of steer (left, photographer David Cook) and damage from stable fly bites in Costa Rica (right, photographer Jose Solórzano).

\section{AREA-WIDE MANAGEMENT}

\subsection{Need for Area-wide Management}

The biology of stable flies necessitates the incorporation of area-wide concepts for their management. Adults are highly vagile, capable of flying up to $30 \mathrm{~km}$ in 24 hours on a flight mill (Bailey et al. 1973) and $8 \mathrm{~km}$ in less than 2 hours in the field. Mean dispersal distance from a natural larval developmental site was $1.5 \mathrm{~km}$ (Taylor et al. 2010), however Hogsette and Ruff (1985) reported individual flies dispersing over $225 \mathrm{~km}$. The dispersal ability of stable flies appears to be limited only by the availability of hosts. They disperse until suitable hosts are located. Because both male and female stable flies require a blood meal prior to mating, most of the dispersing flies appear to be physiologically young. The efficacy of managing stable flies on individual premises, or focusing control efforts to locations where populations 
exceed the economic threshold, is limited by the ability of flies to disperse from premises and locations with no stable fly control to those attempting to control this pest.

Insects are best targeted for control when they are concentrated, immobile and accessible (Horsfall 1985). For stable flies, as for most pestiferous Diptera, this would be during the immature or larval stage. However, stable fly larval developmental substrates are diverse, dispersed and often difficult to locate. Stable fly larvae have been observed in a broad variety of substrates including flotsam containing decomposing mayfly exuvia (Pickard 1968), aquatic plants (King and Lenert 1936; Simmons and Dove 1941), livestock wastes (Meyer and Petersen 1983; Broce et al. 2005), agronomic wastes (Bishopp 1913; Dove and Simmons 1941; Solórzano et al. 2015; Cook et al. 2011, 2017), grass clippings (Silverly and Schoof 1955; Todd 1964) and sewage sludge (Doud et al. 2012).

Beyond "fermenting organic material", little is known about the biological, chemical and physical factors defining developmental substrates (Gilles et al. 2008; Wienhold and Taylor 2012; Friesen et al. 2016). An active microbial community is necessary for larval development (Lysyk et al. 1999; Romero et al. 2006). As the number of coliform bacteria declines with microbial succession, so does the suitability of the substrate for stable fly development (Talley et al. 2009). Because substrates are suitable for stable fly development only during specific phases of decomposition, developmental sites are most often ephemeral, supporting only one generation of flies (Talley et al. 2009; Taylor and Berkebile 2011). These sites are broadly dispersed throughout rural and urban landscapes. Even relatively small sites can produce large numbers of flies (Todd 1964; Patterson and Morgan 1986). These characteristics complicate our ability to locate larval developmental sites for management prior to adult emergence.

Because of their painful bites and persistent feeding behaviour, just a few stable flies can reduce the productivity of livestock, harass companion animals and disrupt human recreational activities. The economic threshold for stable flies on feeder cattle in feedlots has been established at five flies per front leg $(\approx 15$ per animal as stable flies preferentially bite the front legs (Campbell and Berry 1989; Berry et al. 1983)), although cattle often exhibit defensive behaviours with fewer flies (Mullens et al. 2006). When infestations reach very high levels, cattle may no longer resist, and mortality may follow (Bishopp 1913).

Classic integrated pest management (IPM) programmes are based upon the concept of initiating control measures only after the pest population reaches an economic threshold (Metcalf and Luckman 1975). Because stable fly larval developmental sites are difficult to locate prior to adult emergence and larvae are intrinsically innocuous, economic thresholds are based upon counts of adult flies biting animals (Campbell and Berry 1989). By the time adult counts exceed the economic threshold, most have already emerged, and it is too late to initiate larval control procedures. Because of the ability of stable flies to move from property to property, the broad range of development sites and substrates, and the relatively low numbers of flies needed to inflict economic damage, effective management must be approached from a preventive, area-wide perspective. 


\subsection{Challenges for Area-wide Management}

Area-wide management programmes often involve the use of mating disruption with pheromones or mass-production and release of insects with reduced reproductive potential. Unfortunately, aspects of stable fly biology are not conducive to the use of mating disruption. Unlike many Lepidoptera, muscoid Diptera such as stable flies lack volatile pheromones (Blomquist et al. 1987) suitable for mating disruption. Rather, their mate recognition pheromones are non-volatile cuticular hydrocarbons which act on contact, or at very close range (Muhammed et al. 1975; Uebel et al. 1975; Carlson and Mackley 1985).

Release of flies with genetic changes, whether induced by irradiation or transgenesis (Box 1), is complicated by three aspects of stable fly biology:

First, both male and female stable flies are obligate hematophages, blood-feeding 1-3 times per day for their entire life (Harris et al. 1974). Releasing large numbers of biting flies will increase the burden on livestock significantly.

Secondly, stable fly populations can be very large. Huge numbers of flies with non-persistent or threshold dependent genetic modifications must be released to attain the ratios necessary for control. Releasing such numbers of painful biters will meet with public protests. Added to this, their ability to disperse requires that even greater numbers be released over wider areas.

Thirdly, because of their high reproductive rate, short of eradication, small populations can recover to outbreak proportions quickly, precluding the concept of releasing flies with genetic changes for a limited period of time when natural populations are low with the hope of retarding later population growth.

\section{Box 1. Non-Persistent and Persistent Genetic Changes}

Genetic changes caused for example by irradiation, or the insertion of external genetic constructs (transgenesis) through modern biotechnology, can reduce the reproductive fitness of an insect. These genetic changes can be non-persistent or persistent in the target pest population (Carter and Friedman 2016). For example, the genetic changes of released sterile insects are non-persistent because they are not expected to persist in the environment. The released insects mate with wild insects reducing their fitness, but their genetic changes are not passed to their progeny. Therefore, programmes releasing insects with non-persistent genetic changes such as the Sterile Insect Technique (SIT) must release them continuously in numbers that greatly exceed the target population, often in the range of 10:1 to 200:1 (Knipling 1955). Because the random dominant mutations induced by irradiation render flies sterile, genetic changes do not persist in the environment, thus these SIT programmes have met broad public acceptance, and several are currently active (Klassen et al. 2021).

Persistent genetic modifications are designed to be, at least temporarily, incorporated into the gene pool of the target reducing either fitness or pathogenicity (Champer et al. 2016). Persistent modifications are often linked with a genetic drive mechanism to allow them to increase their frequency in the pest population. Genetic drive constructs can be subdivided into threshold dependent and threshold independent (Carter and Friedman 2016). The frequency of threshold dependent constructs must exceed a given level, the threshold, before increasing in frequency. Threshold independent constructs can theoretically be introduced into a population at a very low level and they will increase their frequency to fixation, replacing the original or natural population. Because these constructs can persist in nature and even replace the natural population, they are receiving a great deal more regulatory and ethical scrutiny than non-persistent technologies. 
Given these constraints, the most viable option for genetic control of stable flies would be to release small numbers of persistent genetically modified flies with a threshold independent gene drive construct. Pending the development of such constructs and public acceptance of the release of such genetically modified organisms that are expected to become established and spread in the pest population (Box 1), our area-wide options for stable fly control are limited to the integrated implementation of traditional management technologies including cultural, biological and chemical methods.

\subsection{Prerequisites for Area-Wide Management}

\subsubsection{Public Support / Consensus / Demand}

Area-wide management programmes are administratively complex and require longer-term commitment (Hendrichs et al. 2007; Vreysen et al. 2007). A primary prerequisite for establishing such a programme is stakeholder collaboration and public recognition of the costs and benefits. This requires effective outreach to ensure that the public is aware of the damages and knowledgeable of the etiological agent.

Outreach is especially important for a pest such as stable flies. Producers often fail to differentiate among the species of muscoid flies associated with livestock. These flies are morphologically similar to the untrained eye. When querying producers about stable fly problems, one frequently hears "no, I don't have a stable fly problem, I have a fly problem." Similarly, when fielding calls from producers seeking assistance with flies, they are rarely able to identify the species of fly with which they are dealing. Smaller species, such as horn flies, are frequently mischaracterized as young flies that will "grow up" into larger flies (flies do not grow after metamorphosis to the adult stage). The biology and management methods for these species differ significantly, making proper identification essential prior to developing management strategies.

In Costa Rica, livestock producers refer to stable flies developing in pineapple fields as "mosca de la piña" and are insistent that they are a different species from the stable fly, "mosca del establo" that they observed prior to the large-scale pineapple production in the country. The importance of education and outreach to gain public support for an area-wide management programme cannot be overemphasized. Economic assessments of the damage are also essential. Annual production losses to the cattle industry from stable flies are estimated to be USD 2.2 billion in the USA (Taylor et al. 2012a), USD 340 million in Brazil (Grisi et al. 2014), and USD 6.8 million in Mexico (Rodríguez-Vivas et al. 2017).

\subsubsection{Regulatory Authority}

Common concerns for area-wide management programmes are "free-riders", individuals who take advantage of the programme, but fail to contribute. This problem is exacerbated when the "problem", in this case stable flies, does not affect source producers, for example crop producers. Stable flies have no negative effects on crop production. Without regulatory authority, it will be very difficult to convince those producers to control the flies developing on their farms. 
In Australia, Brazil, and Costa Rica, there have been public calls and demands for regulatory actions by the governments to address stable flies. The governments of those countries have enacted policies requiring agronomic producers to manage stable flies developing on their properties. In the USA, no such public demands have been made and regulatory policies have not been enacted. Public demand and pressure may ultimately lead to the development of regulation of stable fly source industries.

\subsubsection{Funding}

Regional differences in the sources and nature of stable fly infestations make detailed discussion of funding for area-wide management programmes beyond the scope of this discussion. In most cases, some degree of public funding will be needed to support the administrative and regulatory framework. Where an industry or agronomic system is deemed responsible for economically significant outbreaks, stable fly management should be considered a production expense. Sources of funding for management of non-commercial sources and research will need to be identified by the regionally interested parties.

\subsection{Management Options}

\subsubsection{Cultural / Sanitation Methods}

Elimination of larval development substrates has always been the primary recommendation for stable fly control (Greene 1993). In the USA, where substrates associated with livestock production are considered primary developmental sites, this largely involves manure management. Piling manure reduces the surface area suitable for stable fly development and allows metabolic heat to raise the substrate temperature to a level where stable fly larvae cannot survive. Covering manure and silage excludes ovipositing females. Spreading manure thinly on fields permits it to dry before stable fly larvae can complete development. Avoiding and removing spilled feed reduces the amount of substrate available for larval development.

Cultural methods can be applied to stable flies developing in agronomic wastes as well. Burying post-harvest vegetable residues with several different types of agricultural machinery and then compacting the soil with a landroller has proven effective for reducing stable fly development in Western Australia (David Cook, personal communication). Burial of waste is less effective for pineapple because of the quantity, 230 tons per hectare (Solórzano et al. 2015). Removal of pineapple waste would rapidly deplete soil fertility and is technically not feasible due to the quantity.

Some cultural methods for reducing stable flies have negative environmental ramifications. For example, burning sugarcane prior to harvest reduces the amount of substrate available for stable fly larval development, but also has serious consequences for air quality. Likewise, disposal of vinasse (a byproduct of ethanol distillation) in bodies of water renders it unsuitable for stable fly development, but it pollutes aquatic ecosystems (Souza Dominghetti et al. 2015). 


\subsubsection{Biological Methods}

Biological control agents for stable flies can be divided into three categories, parasitoids, predators, and pathogens. Under natural conditions, egg to adult mortality of stable flies is estimated to exceed $95 \%$, about half of which can be attributed to parasitoids and predators (Smith et al. 1985). The remainder is the result of pathogens and environmental stressors.

Pupal parasitoids are the most commonly used biological control agent for filth flies (Rueda and Axtell 1985; Machtinger et al. 2015). Two genera of pteromalid wasps, Muscidifurax and Spalangia, are frequently observed parasitizing stable flies in North America with 2 and 4 relatively common species, respectively. Several species, including both genera, can be seen in individual collections. How these parasitoids partition their resources is not clear.

The efficacy of augmentative releases of parasitoids is equivocal. Several studies indicated released parasitoids decreased fly populations (Weinzier and Jones 1998; Skovgård 2004; Geden and Hogsette 2006), while others failed to show a significant effect (Meyer et al. 1990; Andress, and Campbell 1994; Skovgård and Nachman 2004). In Costa Rica, two species of parasitoids have been collected from stable fly pupae in pineapple residues, Muscidifurax raptoroides Kogan \& Legner and Spalangia gemina Boucek (unpublished observations), and a pilot programme using inundative releases of Spalangia endius Walker is showing promising results (Solórzano et al. 2017).

Several predators have been observed feeding on immature stable flies including macrochelid mites and staphylinid beetles (Smith et al. 1987; Seymour and Campbell 1993). Augmenting predator populations has not been evaluated for stable fly control.

Pathogens of stable fly were reviewed by Greenberg (1977). Entomopathogenic fungi have been evaluated for control of immature (Moraes et al. 2008, 2010; Alves et al. 2012; Machtinger et al. 2016) and adult (López-Sánchez et al. 2012; CruzVázquez et al. 2015; Weeks et al. 2017) stable flies. Various formulations are commercially available. Several studies have evaluated entomopathogenic nematodes in the genera Heterorhabditis and Steinernema for filth fly control. In laboratory assays, results have been very promising (Taylor et al. 1998; Mahmoud et al. 2007). However, field trials have been disappointing (unpublished data). Although we observed slightly reduced numbers of flies emerging from sites treated with nematodes, we were unable to find infected fly larvae or detect infective juvenile nematodes more than 24 hours after treatment using sentinel greater wax moth larvae Galleria mellonella L.

\subsubsection{Traps and Targets}

The majority of stable fly traps are based upon visual attractants with a sticky surface to catch the flies. Williams (1973) recognized that Alsynite ${ }^{\circledR}$ fiberglass panels selectively attracted stable flies and Broce (1988) modified the trap making it more efficient and resistant to windy conditions. The next generation of traps was derived from blue and black fabric traps designed for tsetse fly (Glossina spp.) control (Mihok et al. 1995). The blue and black fabric traps are of limited utility in temperate parts of North America where sticky traps outperform them and they are susceptible to damage from gnawing insects such as grasshoppers (Orthoptera: Acrididae) 
(Taylor and Berkebile 2006). However, in tropical regions such as La Réunion Island, they have proven to be very effective, especially the Vavoua trap (Laveissière and Grébaut 1990; Gilles et al. 2007).

In Costa Rica, improvised traps constructed from white plastic bags coated with an adhesive (Fig. 2) have been employed by the thousands for control of stable flies around pineapple plantations (Solórzano et al. 2015). These traps must be replaced every 1-2 days because they become saturated with insects and lose their effectiveness (Beresford and Sutcliffe 2017). Because of the environmental impact of disposing of such large numbers of plastic bags, research is currently underway to replace the white traps with insecticide-treated Vavoua traps.

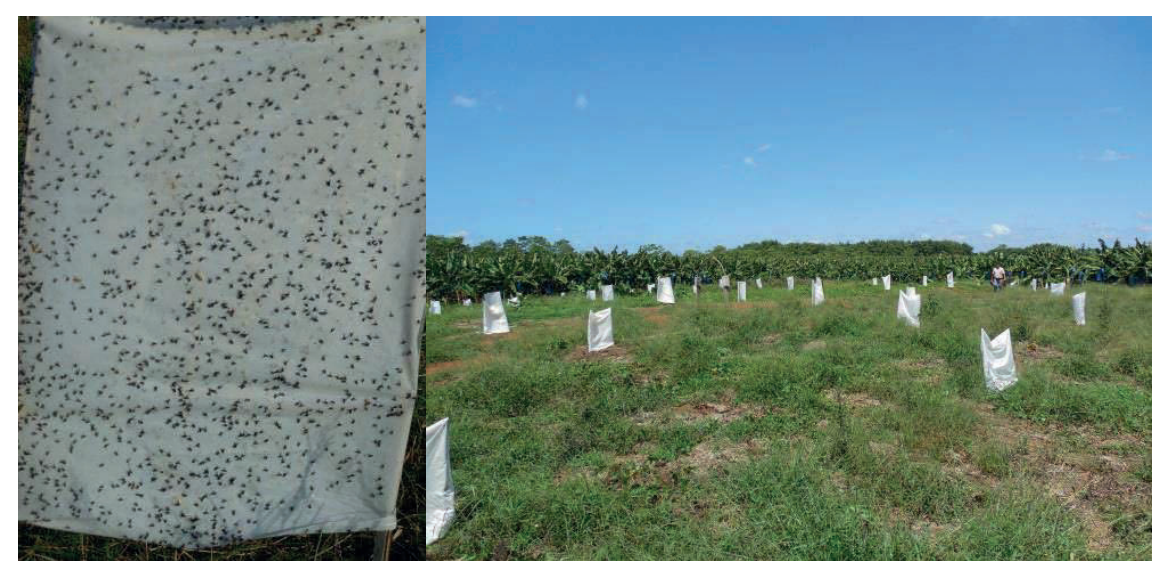

Figure 2. Sticky traps used for stable fly control in Costa Rica.

Targets are like traps, but they intoxicate the attracted insects rather than catch them. Therefore, they do not need to be emptied or replaced routinely. Meifert et al. (1978) developed an early target system for stable flies by applying permethrin to the fiberglass panels of the William's trap. They indicated that the system was able to reduce the stable fly population by $30 \%$ per day when employed at a density of one target for every five animals. Blue and black targets are a modification of the blue and black traps (Foil and Younger 2006). When impregnated with $0.1 \% \lambda$-cyhalothrin or $0.1 \% \zeta$-cypermethrin targets remain effective for $\approx 4$ months (Hogsette et al. 2008). In a study in Louisiana, an average of 220 stable flies landed per hour on targets long enough to be intoxicated (Hogsette and Foil 2018).

A disadvantage of the targets relative to traps is that they cannot be used to quantify the number of flies in the population nor the number of flies killed. In addition, targets provide less psychological satisfaction because dead or trapped flies are not apparent. However, both of these concerns can be mitigated by placement of sticky traps adjacent to selected targets (Foil and Younger 2006). 


\subsubsection{Chemical Control}

- Immatures. Because substrates for stable fly larval development tend to be microbially very active (Romero et al. 2006; Talley et al. 2009; Scully et al. 2017), most insecticides applied to substrates tend to degrade quickly and have little residual activity. Two classes of insect growth regulators (IGRs), cyromazine and benzoylureas have proven to be the most effective for controlling stable fly larvae (Taylor et al. 2012b, 2014; Solórzano et al. 2015). A single application of these compounds can provide 12 or more weeks of control and they have relatively low vertebrate toxicity (Tunaz and Uygun 2004). Cyromazine and benzoylureas belong to different insecticide mode of action classes with distinct resistance mechanisms (Keiding et al. 1991; IRAC 2017). Therefore, they are suitable for rotation to reduce the development of insecticide resistance. In addition, cyromazine and benzoylureas are compatible with biological control using parasitoids (Ables et al. 1975; Morgan and Patterson 1990).

- Adults. Chemical options for controlling adult stable flies associated with food animals such as cattle are limited. Premise or area sprays should be reserved as a last resort for outbreaks where other control measures have failed. Pyrethroids remain effective, although resistance has been detected (Cilek and Greene 1994; Olafson et al. 2011). Their continued effectiveness is probably a reflection of the low efficiency of treatments (Greene 1993). Insecticide-impregnated netting provided as resting sites near livestock are showing promise, especially in the dairy environment. In a study in Nebraska, $\approx 1000$ meters of netting were installed on the periphery of two dairy barns. Up to 60 stable flies per linear meter per day were collected dead beneath the netting. Based upon observations, we estimate that the collections represented less than $10 \%$ of the flies that were lethally intoxicated (unpublished data). As methods for targeting stable flies with insecticides improve, resistance will become a greater problem.

\subsubsection{On-Animal}

On-animal strategies include physical protection or barriers such as boots, masks, sheets, etc., and chemical agents such as repellents and insecticides. Physical protection is frequently used for high value animals such as horses, but it is not practical for livestock such as cattle.

On-animal chemical technologies such as ear tags and pour-on insecticides are commonly used to protect livestock from horn flies. However, because stable flies spend little time on the host and bite primarily on the lower legs, these technologies are less effective against them (Foil and Hogsette 1994; Broce et al. 2005). The primary disadvantage of on-animal chemical treatments is that they have short residual activity against stable flies, less than 3-4 days for most and less than 6-8 hours for many (Foil and Hogsette 1994; Mullens et al. 2009; Benelli and Pavela 2018). A combination of fipronil and permethrin provided 5 weeks of repellence when applied to dogs in the laboratory (Fankhauser et al. 2015); however, this formulation has not been tested on livestock in pastures. 


\subsection{Area-Wide Strategy for Stable Flies}

With the current state of technology, management strategies incorporating the release of large numbers of biting, sterile or genetically modified, stable flies are unlikely to be accepted by livestock producers or the public. Pending the development, and public acceptance, of threshold independent genetic drive mechanisms for stable flies, management options are limited to the area-wide application and integration of traditional methods such as cultural, biological and chemical.

Cultural management of animal and vegetative wastes should be the first priority. In an area-wide programme, especially if agronomic systems are contributing significant numbers of flies, such control will need to be mandated along with inspection and enforcement systems. Most of the currently recognized larval developmental substrates originate from human activities, and therefore are more manageable. Those developmental substrates that cannot be rendered unsuitable for stable fly development by cultural methods will need to be treated with biological and/or chemical control agents. Although biological control programmes on stable flies have had inconsistent results, pteromalid parasitoids are the most developed option. IGRs are the most effective and environmentally sound chemical alternatives available. Insecticide resistance management including rotation of insecticides with distinct modes of action must be included for a sustainable management plan.

A concerted effort must be made to identify and remediate all larval developmental sites within the control region. Management of larval developmental sites must be the primary emphasis of an area-wide stable fly management programme. However, outbreaks of adult flies due to control failure or unanticipated developmental sites are still likely to occur. Adult stable flies need to be managed in the vicinity of the developmental sites and susceptible hosts including humans and livestock. Traps, targets and insecticide impregnated artificial resting sites are the best options for managing adult stable flies. On-animal insecticides and repellents may be necessary for short-term remediation in cases where other control measures failed, but these are best applied on a premise by premise basis and in pest hot spots, rather than an area-wide basis.

Depending upon the situation, one cultural method such as burying vegetable residues may be adequate to control a stable fly problem. Alternatively, multiple strategies including both larval and adult control may be required if no single technology is adequately effective. Reliance upon chemical control alone is shortsighted and will lead to insecticide resistance and eventual loss of control. Cultural, and often biological, control efforts should accompany chemical control.

\subsection{Research Needs}

Because area-wide management of stable flies is dependent upon reducing and eliminating larval developmental sites, it is imperative that we develop a better understanding of the biological, environmental and physical characteristics of developmental substrates. In addition to the developmental substrates discussed in Section 2, developmental sites which do not fit into the current paradigm appear to be contributing to the adult stable fly populations (unpublished data). Recognized 
larval developmental sites tend to have high densities of larvae restricted to small areas. Is it possible that we are overlooking a second type of developmental sites, those with low densities of larvae, possibly one or two per square meter, but distributed over many hectares of land? Possibilities include crop residues in agronomic fields and grass and other plant residues (thatch) in grasslands. If such "low-density, large-area" developmental sites are widespread, then a very different approach to stable fly management will be needed. A better understanding of developmental substrates will help with the development of cultural and mechanical methods to render substrates unsuitable for stable flies as well.

A second research priority is a better understanding of the population dynamics of both larval and adult stable flies. How are females locating oviposition sites and how are larvae utilizing the substrates? What environmental factors are driving dispersal and population fluctuations? How far are adults dispersing? Incorporation of this information into area-wide management projects will improve their efficiency greatly.

Lastly, improved adult suppression systems are needed; more efficient traps and targets requiring less maintenance and novel adult suppression methods will add greatly to management programmes. It is unlikely we will ever be able to locate and remediate all larval developmental sites within the potential dispersal distance of stable flies. Therefore, adult suppression will remain an important component of any management programme.

\subsection{Education and Outreach}

An area-wide management programme for stable flies must include an educational component. Primary to this effort is information on the types of flies associated with livestock, their biology and effects on the productivity and comfort of the animals. Education will improve public support from both political and applied perspectives. Without such education, a successful area-wide programme may be perceived by the public as a failure if infestations of other species of muscoid flies continue and cannot be differentiated from stable flies. Livestock producers and landowners should also be aware of the natural enemies of flies and methods to preserve and augment their populations.

All levels of the distribution chain for chemical control agents from producers and suppliers to cattlemen must know their proper use for the species of flies affecting livestock production systems.

\section{REFERENCES}

Ables, J. R., R. P. West, and M. Shepard. 1975. Response of the house fly and its parasitoids to Dimilin (TH-6040)12. Journal of Economic Entomology 68: 622-624.

Alves, P. S. A., A. P. R. Moraes, C. M. C. de Salles, V. R. E. P. Bittencourt, and A. J. Bittencourt. 2012. Lecanicillium lecanii for control of the immature stage of Stomoxys calcitrans. Revista Brasileira de Medicina Veterinaria 34 (Suppl. 1): 66-72.

Anderson, J. R. 1978. Mating behavior of Stomoxys calcitrans: Effects of a blood meal on the mating drive of males and its necessity as a prerequisite for proper insemination of females. Journal of Economic Entomology 71: 379-386. 
Anderson, J. R., and C. H. Tempelis. 1970. Precipitin test identification of blood meals of Stomoxys calcitrans (L.) caught on California poultry ranches, and observations of digestion rates of bovine and citrated human blood. Journal of Medical Entomology 7: 223-229.

Andress, E. R., and J. B. Campbell. 1994. Inundative releases of pteromalid parasitoids (Hymenoptera: Pteromalidae) for the control of stable flies, Stomoxys calcitrans (L.) (Diptera: Muscidae) at confined cattle installations in west central Nebraska. Journal of Economic Entomology 87: 714-722.

Bailey, D. L., T. L. Whitfield, and B. J. Smittle. 1973. Flight and dispersal of the stable fly. Journal of Economic Entomology 66: 410-411.

Benelli, G., and R. Pavela. 2018. Beyond mosquitoes-Essential oil toxicity and repellency against bloodsucking insects. Industrial Crops and Products 117: 382-392.

Beresford, D. V., and J. F. Sutcliffe. 2017. Evidence for sticky-trap avoidance by stable fly, Stomoxys calcitrans (Diptera: Muscidae), in response to trapped flies. Journal of the American Mosquito Control Association 33: 250-252.

Berry, I. L., D. A. Stage, and J. B. Campbell. 1983. Populations and economic impacts of stable flies on cattle Stomoxys calcitrans, Nebraska, production losses. Transactions of the American Society of Agricultural Engineers 26: 873-877.

Bishopp, F. C. 1913. The stable fly (Stomoxys calcitrans L.), an important livestock pest. Journal of Economic Entomology 6: 112-126.

Blomquist, G. J., J. W. Dillwith, and T. S. Adams. 1987. Biosynthesis and endocrine regulation of sex pheromone production in Diptera, pp. 217-250. In G. D. Prestwich and G. J. Blomquist (eds.), Pheromone biochemistry. Academic Press, New York, NY, USA.

Broce, A. B. 1988. An improved alsynite trap for stable flies, Stomoxys calcitrans (Diptera: Muscidae). Journal of Medical Entomology 25: 406-409.

Broce, A. B., J. Hogsette, and S. Paisley. 2005. Winter feeding sites of hay in round bales as major developmental sites of Stomoxys calcitrans (Diptera: Muscidae) in pastures in spring and summer. Journal of Economic Entomology 98: 2307-2312.

Campbell, J. B., and C. D. McNeal. 1979. A guide to Integrated Pest Management at feedlots and dairies. Nebraska University College of Agriculture and Home Economics Extension Circular EC 80-1536. Lincoln, Nebraska, USA.

Campbell, J. B., and I. L. Berry 1989. Economic threshold for stable flies on confined livestock, pp. 18 22. In J. J. Petersen and G. L. Greene (eds.), Current status of stable fly (Diptera: Muscidae) research. Miscellaneous Publications of the Entomological Society of America 74.

Campbell, J. B., M. A. Catangui, G. D. Thomas, D. J. Boxler, and R. Davis. 1993. Effects of stable flies (Diptera, Muscidae) and heat stress on weight gain and feed conversion of feeder cattle. Journal of Agricultural Entomology 10: 155-161.

Campbell, J. B., S. R. Skoda, D. R. Berkebile, D. J. Boxler, G. D. Thomas, D. C. Adams, and R. Davis. 2001. Effects of stable flies (Diptera: Muscidae) on weight gains of grazing yearling cattle. Journal of Economic Entomology 94: 780-783.

Carlson, D. A., and J. W. Mackley. 1985. Polyunsaturated hydrocarbons in the stable fly. Journal of Chemical Ecology 11: 1485-1496.

Carter, S. R., and R. M. Friedman. 2016. Policy and regulatory issues for gene drives in insects. Workshop report. J. Craig Venter Institute's Policy Center and University of California at San Diego, USA. 21 pp.

Champer, J., A. Buchman, and O. S. Akbari. 2016. Cheating evolution: Engineering gene drives to manipulate the fate of wild populations. Nature Reviews Genetics 17: 146-159.

Cilek, J. E., and G. L. Greene. 1994. Stable fly (Diptera: Muscidae) insecticide resistance in Kansas cattle feedlots. Journal of Economic Entomology 87: 275-279.

Cook, D. F., I. R. Dadour, and N. J. Keals. 1999. Stable fly, house fly (Diptera: Muscidae), and other nuisance fly development in poultry litter associated with horticultural crop production. Journal of Economic Entomology 92: 1352-1357.

Cook, D. F., I. R. Dadour, and S. C. Voss. 2011. Management of stable fly and other nuisance flies breeding in rotting vegetable matter associated with horticultural crop production. International Journal of Pest Management 57: 315-320.

Cook, D. F., D. V. Telfer, J. B. Lindsey, and R. A. Deyl. 2017. Substrates across horticultural and livestock industries that support the development of stable fly, Stomoxys calcitrans (Diptera: Muscidae). Austral Entomology 57: 344-348. 
Cruz-Vázquez, C., J. Carvajal Márquez, R. Lezama-Gutiérrez, I. Vitela-Mendoza, and M. RamosParra. 2015. Efficacy of the entomopathogenic fungi Metarhizium anisopliae in the control of infestation by stable flies, Stomoxys calcitrans (L.), under natural infestation conditions. Veterinary Parasitology 212: 350-355.

Dougherty, C. T., F. W. Knapp, P. B. Burrus, D. C. Willis, P. L. Cornelius, and N. W. Bradley. 1993. Multiple releases of stable flies (Stomoxys calcitrans L.) and behavior of grazing beef cattle. Applied Animal Behaviour Science 38: 191-212.

Dougherty, C. T., F. W. Knapp, P. B. Burrus, D. C. Willis, and P. L. Cornelius. 1994. Moderation of grazing behavior of beef cattle by stable flies (Stomoxys calcitrans L.). Applied Animal Behaviour Science 40: 113-127.

Dougherty, C. T., F. W. Knapp, P. B. Burrus, D. C. Willis, and P. L. Cornelius. 1995. Behavior of grazing cattle exposed to small populations of stable flies (Stomoxys calcitrans L.). Applied Animal Behaviour Science 42: 231-248.

Doud, C. W., D. B. Taylor, and L. Zurek. 2012. Dewatered sewage biosolids provide a productive larval habitat for stable flies and house flies (Diptera: Muscidae). Journal of Medical Entomology 49: 286292.

Dove, W. E., and S. W. Simmons. 1941. Control of dog fly breeding in peanut litter. USDA, Bureau of Entomology and Plant Quarantine, E-542.

Dove, W. E., and S. W. Simmons. 1942. Creosote oil with water for control of the stable fly, or "dog fly," in drifts of marine grasses. Journal of Economic Entomology 35: 589-592.

Elkan, P. W., R. Parnell, and J. L. David Smith. 2009. A die-off of large ungulates following a Stomoxys biting fly out-break in lowland forest, northern Republic of Congo. African Journal of Ecology 47: $528-536$.

Fankhauser, B., J. P. Irwin, M. L. Stone, S. T. Chester, and M. D. Soll. 2015. Repellent and insecticidal efficacy of a new combination of fipronil and permethrin against stable flies (Stomoxys calcitrans). Parasites \& Vectors 8: 61.

Foil, L. D., and J. A. Hogsette. 1994. Biology and control of tabanids, stable flies and horn flies. Scientific and technical review of the Office International des Epizooties (Paris) 13: 1125-1158.

Foil, L. D., and C. D. Younger. 2006. Development of treated targets for controlling stable flies (Diptera: Muscidae). Veterinary Parasitology 137: 311-315.

Friesen, K. M., D. R. Berkebile, B. J. Wienhold, L. M. Durso, J. J. Zhu, and D. B Taylor. 2016. Environmental parameters associated with stable fly (Diptera: Muscidae) development at hay feeding sites. Environmental Entomology 45: 570-576.

Geden, C. J., and J. A. Hogsette. 2006. Suppression of house flies (Diptera: Muscidae) in Florida poultry houses by sustained releases of Muscidifurax raptorellus and Spalangia cameroni (Hymenoptera: Pteromalidae). Environmental Entomology 35: 75-82.

Gilles, J., J.-F. David, G. Duvallet, S. de la Rocque, and E. Tillard. 2007. Efficiency of traps for Stomoxys calcitrans and Stomoxys niger niger on Réunion Island. Medical and Veterinary Entomology 21: 65-69.

Gilles, J., J.-F. David, P. Lecomte, and E. Tillard. 2008. Relationships between chemical properties of larval media and development of two Stomoxys species (Diptera: Muscidae) from Réunion Island. Environmental Entomology 37: 45-50.

Greenberg, B. 1977. Pathogens of Stomoxys calcitrans (stable flies). Bulletin of the World Health Organization 55 (Suppl. 1): 259-261.

Greene, G. L. 1993. Chemical, cultural, and mechanical control of stable flies and house flies, pp. 83-90. In G. D. Thomas and S. R. Skoda (eds.), Rural flies in the urban environment. North Central Regional Research Publication No. 335, Institute of Agriculture and Natural Resources, University of Nebraska, Lincoln, Nebraska, USA.

Grisi, L., R. Cerqueira-Leite, J. R. de Souza Martins, A. T. Medeiros de Barros, R. Andreotti, P. H. D. Cançado, A. A. Pérez de León, J. Barros Pereira, and H. Silva Villela. 2014. Reassessment of the potential economic impact of cattle parasites in Brazil. Brazilian Journal of Veterinary Parasitology 23: 150-156.

Hafez, M., and F. M. Gamal-Eddin. 1959. Ecological studies on Stomoxys calcitrans L. and sitiens Rond. in Egypt, with suggestions on their control (Diptera: Muscidae). Bulletin de la Société Entomologique d'Égypte 43: 245-283.

Hall, R. D., G. D. Thomas, and C. E. Morgan. 1982. Stable flies, Stomoxys calcitrans (L.), breeding in large round hay bales: Initial associations (Diptera: Muscidae). Journal of the Kansas Entomological Society 55: 617-620. 
Harris, R. L., J. A. Miller, and E. D. Frazer. 1974. Horn flies and stable flies feeding activity. Annals Entomological Society of America 67: 891-894.

Hendrichs, J., P. Kenmore, A. S. Robinson, and M. J. B. Vreysen. 2007. Area-Wide Integrated Pest Management (AW-IPM): Principles, practice and prospects, pp. 3-33. In M. J. B. Vreysen, A. S. Robinson, and J. Hendrichs (eds.), Area-wide control of insect pests: From research to field implementation. Springer, Dordrecht, The Netherlands.

Herrero, M. V., L. Montes., C. Sanabria, A. Sánchez, and R. Hernández. 1989. Estudio inicial sobre la mosca de los establos, Stomoxys calcitrans (Diptera: Muscidae), en la región del Pacífico Sur de Costa Rica. Ciencias Veterinarias (Heredia, Costa Rica) 11: 11-14.

Herrero, M. V., L. Montes-Pico, and R. Hernández. 1991. Abundancia relativa de Stomoxys calcitrans (L.) (Diptera: Muscidae) en seis localidades del Pacífico Sur de Costa Rica. Revista de Biología Tropical 39: 309-310.

Hogsette, J. A., and J. P. Ruff. 1985. Stable fly (Diptera: Muscidae) migration in northwest Florida. Environmental Entomology 14: 170-175.

Hogsette, J. A., and L. D. Foil. 2018. Blue and black cloth targets: Effects of size, shape and color on stable fly (L.) (Diptera: Muscidae) attraction. Journal of Economic Entomology 111: 974-979.

Hogsette, J. A., J. P. Ruff, and C. J. Jones. 1987. Stable fly biology and control in northwest Florida. Journal of Agricultural Entomology 4: 1-11.

Hogsette, J. A., A. Nalli, and L. D. Foil. 2008. Evaluation of different insecticides and fabric types for development of treated targets for stable fly (Diptera: Muscidae) control. Journal of Economic Entomology 101: 1034-1038.

Horsfall, W. R. 1985. Mosquito abatement in a changing world. Journal of the American Mosquito Control Association 1: 135-138.

(IRAC) Insecticide Resistance Action Committee. 2017. IRAC mode of action classification scheme. Version 9.1. CropLife International.

Keiding, J., J. B. Jespersen, and A. S. El-Khodary. 1991. Resistance risk assessment of two insect development inhibitors, diflubenzuron and cyromazine, for control of the housefly Musca domestica. Part I: Larvicidal tests with insecticide-resistant laboratory and Danish field populations. Pesticide Science 32: 187-206.

King, W. V., and L. G. Lenert. 1936. Outbreaks of Stomoxys calcitrans L. ("dog flies") along Florida's northwest coast. Florida Entomologist 19: 33-39.

Klassen, W., C. F. Curtis, and J. Hendrichs. 2021. History of the Sterile Insect Technique, pp. 1-44. In V. A. Dyck, J. Hendrichs, and A. S. Robinson (eds.), Sterile Insect Technique - Principles and practice in Area-Wide Integrated Pest Management. Second Edition. CRC Press, Boca Raton, Florida, USA.

Knipling, E. F. 1955. Possibilities of insect control or eradication through the use of sexually sterile males. Journal of Economic Entomology 48: 459-462.

Koller, W. W., J. B. Catto, I. Bianchin, C. O. Soares, F. Paiva, L. E. R. Tavares, and G. Graciolli. 2009. Surtos da mosca-dos-estábulos, Stomoxys calcitrans, em Mato Grosso do Sul: novo problema para as cadeias produtivas da carne e sucroalcooleira? Documentos 175, Embrapa Gado de Corte, Campo Grande, Mato Grosso do Sul, Brazil. 31 pp.

Kunz, S. E., and J. Monty. 1976. Biology and ecology of Stomoxys nigra Marquart and Stomoxys calcitrans (L.) (Diptera: Muscidae) in Mauritius. Bulletin of Entomological Research 66: 745-755.

Laveissière, C., and P. Grébaut. 1990. Recherches sur les pièges à glossines (Diptera: Glossinidae). Mise au point d'un modèle économique: le piège "Vavoua". Tropical Medicine and Parasitology 41: 185192.

López-Sánchez, J., C. Cruz-Vázquez, R. Lezama-Gutiérrez, and M. Ramos-Parra. 2012. Effect of entomopathogenic fungi upon adults of Stomoxys calcitrans and Musca domestica (Diptera: Muscidae). Biocontrol Science and Technology 22: 969-973.

Lysyk, T., L. Kalischuk-Tymensen, L. Selinger, R. Lancaster, L. Wever, and K. Cheng. 1999. Rearing stable fly larvae (Diptera: Muscidae) on an egg yolk medium. Journal of Medical Entomology 38: 382-388.

Machtinger, E. T., C. J. Geden, P. E. Kaufman, and A. M. House. 2015. Use of pupal parasitoids as biological control agents of filth flies on equine facilities. Journal of Integrated Pest Management 6: 16.

Machtinger, E. T., E. N. I. Weeks, and C. J. Geden. 2016. Oviposition deterrence and immature survival of filth flies (Diptera: Muscidae) when exposed to commercial fungal products. Journal of Insect Science 16: 33253. 
Mahmoud, M. F., N. S. Mandour, and Y. I. Pomazkov. 2007. Efficacy of the entomopathogenic nematode Steinernema feltiae cross N 33 against larvae and pupae of four fly species in the laboratory. Nematologia Mediterranea 35: 221-226.

Meifert, D. W., R. S. Patterson, T. Whitfield, G. C. LaBrecque, and D. E. Weidhaas. 1978. Unique attractant-toxicant system to control stable fly populations. Journal of Economic Entomology 71:290 292.

Metcalf, R. L., and W. H. Luckman. 1975. Introduction to insect pest management. John Wiley \& Sons, New York, USA.

Meyer, J. A., and J. J. Petersen. 1983. Characterization and seasonal distribution of breeding sites of stable flies and house flies (Diptera: Muscidae) on eastern Nebraska feedlots and dairies. Journal of Economic Entomology 76: 103-108.

Meyer, J. A., B. A. Mullens, T. L. Cyr, and C. Stokes. 1990. Commercial and naturally occurring fly parasitoids (Hymenoptera: Pteromalidae) as biological control agents of stable flies and house flies (Diptera: Muscidae) on California dairies. Journal of Economic Entomology 83: 799-806.

Mihok, S., E. K. Kang'ethe, and G. K. Kamau. 1995. Trials of traps and attractants for Stomoxys spp. (Diptera: Muscidae). Journal of Medical Entomology 32: 283-289.

Moon, R. D. 2002. Muscid flies (Muscidae), pp. 279-316. In G. Mullen, and L. Durden (eds.), Medical and veterinary entomology. Academic Press, San Diego, California, USA.

Moraes, A. P. R., I. D. C. Angelo, E. K. K. Fernandes, V. R. E. P. Bittencourt, and A. J. Bittencourt. 2008. Virulence of Metarhizium anisopliae to eggs and immature stages of Stomoxys calcitrans. Annals of the New York Academy of Sciences 1149: 384-387.

Moraes, A. P. R., V. R. E. P. Bittencourt, and A. J. Bittencourt. 2010. Pathogenicity of Beauveria bassiana on immature stages of Stomoxys calcitrans. Ciencia Rural 40: 1802-1807.

Morgan, P. B., and R. S. Patterson. 1990. Efficiency of target formulations of pesticides plus augmentative releases of Spalangia endius Walker (Hymenoptera: Pteromalidae) to suppress populations of Musca domestica L. (Diptera: Muscidae) at poultry installations in the southeastern United States, pp. 69-78. In D. A. Rutz, and R. S. Patterson (eds.), Biocontrol of arthropods affecting livestock and poultry. Westview Press, Boulder, Colorado, USA.

Muhammed, S., Butler, J. F, and Carlson, D. A. 1975. Stable fly sex attractant and mating pheromones found in female body hydrocarbons. Journal of Chemical Ecology 1: 387-398.

Mullens, B. A., W. G. Reifenrath, and S. M. Butler. 2009. Laboratory trials of fatty acids as repellents or antifeedants against house flies, horn flies and stable flies (Diptera: Muscidae). Pest Management Science 65: 1360-1366.

Mullens, B. A., K.-S. Lii, Y. Mao, J. A. Meyer, N. G. Peterson, and C. E. Szijj. 2006. Behavioural responses of dairy cattle to the stable fly, Stomoxys calcitrans, in an open field environment. Medical and Veterinary Entomology 20: 122-137.

Newson, H. D. 1977. Arthropod problems in recreation areas. Annual Review of Entomology 22: 333353.

Olafson, P. U., J. B. Pitzer, and P. E. Kaufman. 2011. Identification of a mutation associated with permethrin resistance in the para-type sodium channel of the stable fly (Diptera: Muscidae). Journal of Economic Entomology 104: 250-257.

Patterson, R. S., and P. B. Morgan. 1986. Factors affecting the use of an IPM scheme at poultry installations in a semitropical climate, pp. 101-107. In R. S. Patterson, and D. A. Rutz (eds.), Biological control of muscoid flies. Miscellaneous Publications of the Entomological Society of America No. 61.

Pickard, E. 1968. Stomoxys calcitrans (L.) breeding along TVA reservoir shorelines. Mosquito News 28: 644-646.

Rodríguez-Vivas, R. I., L. Grisi, A. A. Pérez de León, H. Silva Villela, J. F. de Jesús Torres-Acosta, H. Fragoso Sánchez, D. Romero Salas, R. Rosario Cruz, F. Saldierna, and D. García Carrasco. 2017. Potential economic impact assessment for cattle parasites in Mexico. Revista Mexicana de Ciencias Pecuarias 8: 61-74.

Romero, A., A. Broce, and L. Zurek. 2006. Role of bacteria in the oviposition behaviour and larval development of stable flies. Medical and Veterinary Entomology 20: 115-121.

Rueda, L. M., and R. C. Axtell. 1985. Guide to common species of pupal parasites (Hymenoptera: Pteromalidae) of the house fly and other muscoid flies associated with poultry and livestock manure. North Carolina Agricultural Research Service Technical Bulletin 278. 
Scully, E., K. Friesen, B. Wienhold, and L. M. Durso. 2017. Microbial communities associated with stable fly (Diptera: Muscidae) larvae and their developmental substrates. Annals of the Entomological Society of America 110: 61-72.

Seymour, R. C., and J. B. Campbell. 1993. Predators and parasitoids of house flies and stable flies (Diptera: Muscidae) in cattle confinements in west central Nebraska. Environmental Entomology 22: 212-219.

Silverly, R. E., and H. F. Schoof. 1955. Utilization of various production media by muscoid flies in a metropolitan area. I. Adaptability of different flies for infestation of prevalent media. Annals Entomological Society of America 48: 258-262.

Simmons, S. W., and W. E. Dove. 1941. Breeding places of the stable fly or "dog fly" Stomoxys calcitrans (L.) in northwestern Florida. Journal Economic Entomology 34: 457-462.

Simmons, S. W., and W. E. Dove. 1942. Waste celery as a breeding medium for the stable fly or "dog fly" with suggestions for control. Journal Economic Entomology 35: 709-715.

Skovgård, H. 2004. Sustained releases of the pupal parasitoid Spalangia cameroni (Hymenoptera: Pteromalidae) for control of house flies, Musca domestica and stable flies Stomoxys calcitrans (Diptera: Muscidae) on dairy farms in Denmark. Biological Control 30: 288-297.

Skovgård, H., and G. Nachman. 2004. Biological control of house flies Musca domestica and stable flies Stomoxys calcitrans (Diptera: Muscidae) by means of inundative releases of Spalangia cameroni (Hymenoptera: Pteromalidae). Bulletin of Entomological Research 94: 555-567.

Smith, J. P., R. D. Hall, and G. D. Thomas. 1985. Field studies on mortality of the immature stages of the stable fly (Diptera: Muscidae). Environmental Entomology14: 881-890.

Smith, J. P., R. D. Hall, and G. D. Thomas. 1987. Arthropod predators and competitors of the stable fly, Stomoxys calcitrans (L.) in central Missouri. Journal Kansas Entomological Society 60: 562-567.

Solórzano, J.-A., J. Gilles, O. Bravo, C. Vargas, Y. Gomez-Bonilla, G. Bingham, and D. B. Taylor. 2015. Biology and trapping of stable flies (Diptera: Muscidae) developing in pineapple residues (Ananas comosus) in Costa Rica. Journal Insect Science 15: 145.

Solórzano, J.-A., H. Mena, R. Romero, J. Treviño, J. Gilles, C. Geden, D. Taylor, and H. Skovgård. 2017. Biological control of livestock pest biting fly Stomoxys calcitrans at agriculture pineapple residues using the parasitoid Spalangia endius reared on irradiated Mediterranean fruit fly: Assessment of parasitism in field and laboratory in Costa Rica, pp. 242-243. In Third FAO/IAEA International Conference on Area-wide Management of Insect Pests, Book of Abstracts. Vienna, Austria.

Souza Dominghetti, T. F. de, A. T. Medeiros de Barros, C. Oliveira Soares, and P. H. Duarte Cançado. 2015. Stomoxys calcitrans (Diptera: Muscidae) outbreaks: Current situation and future outlook with emphasis on Brazil. Brazilian Journal of Veterinary Parasitology 24: 387-395.

Talley, J., A. Broce, and L. Zurek. 2009. Characterization of stable fly (Diptera: Muscidae) larval development habitat at round hay bale feeding sites. Journal of Medical Entomology 46: 1310-1319.

Taylor, D. B., and D. R. Berkebile. 2006. Comparative efficiency of six stable fly traps. Journal Economic Entomology 99: 1415-1419.

Taylor, D. B., and D. R. Berkebile. 2011. Phenology of stable fly (Diptera: Muscidae) larvae in round bale hay feeding sites in eastern Nebraska. Environmental Entomology 40: 184-193.

Taylor, D. B., R. D. Moon, and D. R. Mark. 2012a. Economic impact of stable flies (Diptera: Muscidae) on cattle production. Journal of Medical Entomology 49: 198-209.

Taylor, D. B., K. Friesen, and J. Zhu. 2014. Stable fly control in cattle winter feeding sites with Novaluron. Arthropod Management Tests 39: 1-2.

Taylor, D. B., A. L. Szalanski, B. J. Adams, and R. D. Peterson II. 1998. Susceptibility of house fly, Musca domestica (Diptera: Muscidae) larvae to entomopathogenic nematodes (Rhabditida: Heterorhabditidae, Steinernematidae). Environmental Entomology 27: 1514-1519.

Taylor, D. B., K. Friesen, J. J. Zhu, and K. Sievert. 2012b. Efficacy of cyromazine to control immature stable flies (Diptera: Muscidae) developing in winter hay feeding sites. Journal of Economic Entomology 105: 726-731.

Taylor, D. B., R. D. Moon, J. B. Campbell, D. R. Berkebile, P. J. Scholl, A. B. Broce, and J. A. Hogsette. 2010. Dispersal of stable flies (Diptera: Muscidae) from larval developmental sites. Environmental Entomology 39: 1101-1110.

Todd, D. H. 1964. The biting fly Stomoxys calcitrans (L.) in dairy herds in New Zealand. New Zealand Journal of Agricultural Research 7: 60-79.

Tunaz, H., and N. Uygun. 2004. Insect growth regulators for insect pest control. Turkish Journal of Agriculture and Forestry 28: 377-387. 
Uebel, E. C., P. E. Sonnet, and R. W. Miller. 1975. Sex pheromone of the stable fly: Isolation and preliminary identification of compounds that induce mating strike behavior. Journal of Chemical Ecology 1: 377-385.

Vreysen, M. J. B., J. Gerardo-Abaya, and J. P. Cayol. 2007. Lessons from Area-Wide Integrated Pest Management (AW-IPM) programmes with an SIT component: An FAO/IAEA perspective, pp. 723744. In M. J. B. Vreysen, A. S. Robinson, and J. Hendrichs (eds.), Area-wide control of insect pests. From research to field implementation. Springer, Dordrecht, The Netherlands.

Weeks, E. N. I., E. T. Machtinger, S. A. Gezan, P. E. Kaufman, and C. J. Geden. 2017. Effects of four commercial fungal formulations on mortality and sporulation in house flies (Musca domestica) and stable flies (Stomoxys calcitrans). Medical and Veterinary Entomology 31: 15-22.

Weinzier, R. A., and C. J. Jones. 1998. Releases of Spalangia nigroaenea and Muscidifurax zaraptor (Hymenoptera: Pteromalidae) increase rates of parasitism and total mortality of stable fly and house fly (Diptera: Muscidae) pupae in Illinois cattle feedlots. Journal Economic Entomology 91: 1114 1121.

Wienhold, B. J., and D. B. Taylor. 2012. Substrate properties of stable fly developmental sites associated with round bale hay feeding sites in eastern Nebraska. Environmental Entomology 41: 213-221.

Williams, D. F. 1973. Sticky traps for sampling populations of Stomoxys calcitrans. Journal of Economic Entomology 66: 1279-1280.

Yeruham, I., and Y. Braverman. 1995. Skin lesions in dogs, horses and calves caused by the stable fly Stomoxys calcitrans (L.) (Diptera: Muscidae). Revue d'Élevage et de Médecine Vétérinaire des Pays Tropicaux 48: 347-349.

Zumpt, F. 1973. The stomoxyine biting flies of the world. Gustav Fischer Verlag, Stuttgart, Germany. 175 pp. 